\title{
Physical Activity Outcome In Early Vs Delayed Elderly Hip Fracture Surgery
}

Anto Gopurathingal ( $\nabla$ aantoh@gmail.com )

Gold Platz Apartments

Amar Kamat

HCG

Method Article

Keywords: Pfna2, trauma, hip

Posted Date: January 20th, 2022

DOI: https://doi.org/10.21203/rs.3.rs-1240719/v1

License: (c) (i) This work is licensed under a Creative Commons Attribution 4.0 International License. Read Full License 


\section{Abstract}

The study aimed to find if an earlier fixation of proximal hip fractures in the elderly, leads to a better outcome, physically and mentally. Current guidelines recommend that hip fracture surgery should be done within 24 hours of injury. But those favoring a delay in surgery believe that it provides sufficient time to medically optimize patients, and thereby decrease the risk for perioperative complication. Our study was carried out in a tertiary care center. A total of 58 patients was enrolled in the study. Analysis showed, in comparison with the delayed fixation group, the early fixation group didn't enjoy a statistically better physical quality of life at the end of 6 months, but mental health scores were significantly above the delayed fixation group. It also showed the most common reason for the delay was late presentation followed by delayed insurance clearance. An increased hospital stay was also seen for the delayed fixation group.

\section{Introduction}

Among elderly patients, hip fractures are associated with a higher in-hospital mortality rate and serious temporary and sometimes profound permanent impairment of self-sufficiency and quality of life.

Current guidelines(1) recommend that surgeons perform hip fracture surgery within 24 hours of injury as observational studies suggest earlier surgery is associated with better functional outcomes. They had shorter hospital stays, better pain control, lower rates of nonunion, lower rates of complications and mortality. Even though guidelines suggest that a delay in surgery of more than 24 hours may not unequivocally impact mortality, these data recommend early surgery on the premise that elderly $(>50-60$ years of age) hip fracture patients are at risk of complications and merit early intervention on humane grounds. (2)

Advocates of early treatment argue that this approach minimizes the duration of time a patient is restricted to bed rest, thereby reducing the risk of associated complications, such as urinary tract infections, deep vein thrombosis, pressure sores, and pneumonia.(3) However, proponents of delay in the timing of surgery believe that it provides ample opportunity to medically optimize patients, and thereby cut back on the risk for perioperative complications (4). A hiccup in the attempt to resolve this uncertainty is the lack of a conventional definition of 'early surgery'. Ambiguity exists about whether $24,48,72$, hours or more should be considered an "undesirable delay" for hip fracture surgery. None of the studies have focussed on the mental health perspective that we have considered here.

\section{Review Of Literature}

Hip fractures represent a progressively important health care problem.

There is a conflicting perception that surgical delay in hip fracture patients is associated with an increase in the duration of hospital stay (5) postoperative complications, and mortality (6). Studies addressing physical activity and mental health outcomes in such patients have rarely been done before. 
In the past, studies have stated that early surgery, operated within 24 hours, is independently associated with a reduced duration of hospital stay (7). In a large prospective observational study, a link was found between surgery within 24 hours and fewer major postoperative complications, in a group of healthier patients, defined as elderly individuals who are devoid of abnormal clinical findings, aortic stenosis, dementia, and end-stage renal disease. But at the end of 6 months, there was no association with mortality $(P=0.09)$. Another retrospective study in 57,315 patients reported an increase in mortality up to 1 year, in the group with a longer delay to surgery. This association was very much strong in patients younger than 70 years of age with no co-morbidities (9).

Considering that life expectancy will be on the rise in the next decade (8), the burden to the healthcare system from hip fractures and their consequences will even greater in the near future.

The prognosis of elderly individuals with proximal hip fractures depends primarily on age, comorbidities, anticoagulation therapy, and the general health status (9). In addition to these, mounting evidence indicates that timing of surgical fixation might play a major role in patient survival after hip fracture (10) (11)

A systematic review in 2010 reported that risk of mortality in elderly patients was reduced by $19 \%$ with early surgery (within 24-72 h) (6). These results reinforced the findings of previous reviews showing that delay of surgery beyond 48 hours increased the mortality within 1 year by $32 \%$ (6). Studies have also shown delayed surgery increased the risk of pneumonia (12).

Although many evidence-based articles recommend surgery of acute hip fracture within the first 48 hours (13), these recommendations are still controversial. Some studies argue that delayed surgical fixation provides valuable time for patients to achieve a better medical condition, which can reduce the risk of perioperative complications, including pneumonia, bleeding, deep venous thrombosis, urinary tract infection, pulmonary embolism, and decubital ulcerations (14). In clinical practice, delayed surgery of hip fractures is quite common because of a limited capacity of operating rooms or personnel, or the need for medical stabilization or anticoagulation reversal of patients before surgery(12).

\section{Materials And Methods}

This study was a prospective, observational design which took place in a tertiary orthopaedic centre with 24 hours availability of orthopaedic operating room and anaesthetist on call. Patients above age of 60 years, who presented with low energy falls and sustained proximal femur fracture viz, neck of Femur, Inter-trochanteric, Sub-trochanteric, were included in the study. Patients who sustained pathological fractures, multiple fractures, high energy trauma like road traffic accidents, and also patients who weren't mobile before the fall due to cerebro-vascular or other events, were excluded from the study. Considering that there will be difference in SF-12 score of 10 units between early fixation and delayed fixation, a sample size of 25 subjects in each group was needed to achieve $80 \%$ power with $5 \%$ level of significance. 
We evaluated the changes in physical activity by using a self reported questionnaire which was measured in terms of SF-12 Questionnaire score. SF-12 Questionnaire score was calculated as per questionnaire answered by the patient or the patient attender either in person, telephonically or via email. Sample T tests were performed to evaluate the changes in SF-12 Questionnaire score from before the fall [pre-fall], to 6 months after surgery. $P$ value $<0.05$ was considered significant.

\section{Observation And Results}

58 patients made the criteria and were included in the study. Follow-up was done till September 2018.

$29(50.0 \%)$ patients were operated within 48 hours of the incident and the rest 29 (50.0\%) patients were operated beyond 48 hours of the incident.

Table 1 and Figure 1 shows the distribution of patients according to age in relation to the timing of surgery.

In the < 48 hours group, 14 (48.3\%) patients were in the age group 60-70 years, $13(44.8 \%)$ patients were in the age group 71-80 years and $2(6.9 \%)$ patients were in the age group > 80 years. In the $>48$ hours group, 24 (82.8\%) patients were in the age group 60-70 years, 5 (17.2\%) patients were in the age group 7180 years and none of the patients were in the age group > 80 years. In < 48 hours group, majority of the patients were in the age group 71-80 years, while in the $>48$ hours group, majority of the patients were in the age group 60-70 years. The mean age in the $<48$ hours group was $67.10 \pm 4.33$ years, while in the $>$ 48 hours group it was $71.17 \pm 6.39$ years. The difference was found to be statistically significant $(p<0.05)$, showing a higher mean age in the $>48$ hours group.

\section{SF-12 PHYSICAL SCORE}

We have done the comparison on the basis of the difference of SF-12 physical score (physical score at pre-fall - physical score at 6 months).

Table 2 shows the difference of SF-12 physical score: The mean difference of SF-12 physical score in the $<48$ hours group was $-11.59 \pm 5.29$, while in the $>48$ hours it was $-14.29 \pm 5.43$. The difference was found to be statistically not significant ( $>0.05)$, showing a comparable difference between the two groups.

\section{SF-12 MENTAL SCORE}

We have done the comparison based on the difference of SF-12 mental score (mental score at pre-fall mental score at 6 months).

Table 3 shows the difference of SF-12 mental score: The mean of difference of SF-12 mental score in the $<48$ hours group was $-3.82 \pm 2.32$, while in the $>48$ hours group it was $-5.66 \pm 4.06$. The difference was found to be statistically significant $(p<0.05)$, showing a larger difference in the $>48$ hours in comparison to the $<48$ hours. 
Table 4 and Figure 2 show the distribution of patients according to the reason for the delay. In the $<48$ hours group, there was no delay, all the $29(100.0 \%)$ reached within 48 hours. In the $>48$ hours group, 14 (48.3\%) were delayed due to late presentation, 7 (24.1\%) patients were delayed due to insurance clearance delay, 4 (13.8\%) patients were delayed due to medical optimization, $3(10.3 \%)$ patients were delayed due to anticoagulant therapy and $1(3.4 \%)$ patient was delayed due to theatre/surgeon unavailability.

Table 5 and Figure 3 show the comparison of mean hospital stay between the $<48$ hours group and $>48$ hours groups.

The mean hospital stay in the $<48$ hours group was $4.66 \pm 0.67$ days, while in the $>48$ hours group it was $5.59 \pm 0.98$ days. The difference was found to be statistically significant $(p<0.05)$, showing a longer hospital stay in the $>48$ hours group.

\section{Discussion}

Several variables are associated with the research question. Most components have a direct effect on outcomes and have been part of discussions in many studies.

Quality of life

In our study, even though patients that were operated within 48 hours had a better quality of life index and they progressed rapidly in rehabilitation, it wasn't statistically significant to be concluded likewise. The mean of difference of SF-12 physical score in the $<48$ hours group was $-14.29 \pm 5.43$, while in the $>$ 48 hours group it was $-11.59 \pm 5.29$. The difference was found to be statistically not significant $(p>0.05)$, showing a comparable difference between the two groups.

Surprisingly, the delayed fixation group had a lesser drop in mental satisfaction compared to the early fixation group.The mean of difference of SF- 12 mental score in the $<48$ hours group was $-5.66 \pm 4.06$, while in the $>48$ hours group it was $-3.82 \pm 2.32$. The difference was found to be statistically significant $(p<0.05)$, showing a larger difference in the $<48$ hours in comparison to the $>48$ hours

Reasons for delay

The most common reason of the delay in our center was late presentation and delay for insurance clearance. In the $>48$ hours group, 14 (48.3\%) were delayed due to late presentation, 7 (24.1\%) patients were delayed due to insurance clearance delay, 4 (13.8\%) patients were delayed due to medical optimization, $3(10.3 \%)$ patients were delayed because they were on anticoagulant therapy and $1(3.4 \%)$ patient was delayed due to theatre/surgeon unavailability.

In literature, the most common reasons for operative delay include the unavailability of the operating room and/or surgical personnel (administrative), and investigation and stabilization of the patient's preoperative medical condition (medical-related)(15). There may be a differential effect for those patients 
delayed for administrative reasons alone compared to those delayed for the optimization of acute medical conditions consequent to their fractured hip.

Mortality

The study period was small to contain such an aspect to our study. We had 2 deaths in our study group which was due to long-term terminal end-stage organ failure, had to be excluded from the study. In a retrospective analysis of 406 patients with proximal femur fractures, Kenzora et al(16) found higher 1year mortality after operative fixation on the first hospital day compared with the second through fifth hospital days (34\% versus $5.8 \%$ ). However, they also reported that a large number of medically unfit patients underwent earlier surgery. Sicker patients may benefit from a delay in order to optimize their medical condition and including these patients in the early surgery group may have diluted the true effect of postponing surgery. For example, Zagrodnick and Kaufner (17)noted a lower in-hospital mortality rate with preoperative stabilization of medical conditions. A prospective study examining a subgroup of 60 acutely ill, hip fracture patients showed a reduction in mortality with surgery delayed more than 24 hours. However, these analyses and observations are not sensitive or powerful enough to detect the effect of early and delayed surgery on unhealthy patients alone. Further, other studies have shown that less healthy patients may still benefit from surgery within 24 hours.(18)

The current evidence suggests that while surgical fixation delay of more than 24 hours may not impact mortality, there is no theoretical advantage for healthier patients to wait for surgery. In fact, there is the potential for increased complications and poorer outcomes.(19) In the case of medically unfit patients, this effect is less clear.

\section{Post operative Complications}

We did not have any surgical complications for our patients within the study period. Surgical timing does not appear to have a significant effect on the number of complications patients may experience after surgery.(20)Yet some studies have shown a significant association between surgical delay (i.e., >24 hours) and the increased incidence of pressure ulcers (21)and avascular necrosis, both complications consistent with extended bed rest. (22)Two prospective studies that adjusted for patients' preoperative health status, age, and gender found a significant and nonsignificant association between time to surgery and a patient's return to independent living status. Where the type of surgery has been shown to affect hip fracture patient outcomes, (20)Al-Ani et al. still found a significantly improved ability of patients undergoing earlier surgery to return to independent living even after adjustment for treatment modality, pre-fracture living status, and walking ability. ${ }^{27}$

In a prospective study of 1206 patients, those who had surgical fixation within 24 hours had significantly fewer post operative days of severe pain(23). Pain can cause stress reaction and subsequent insulin resistance to amplify the process of muscle loss and weakness, which can delay patient rehabilitation and increase the risk of delirium. However, most of these studies are flawed by retrospective design and heterogeneity. In the absence of a prospective, randomized study comparing delayed and expeditious 
surgery, it is tough to know whether surgical fixation delay adversely affects outcomes directly or if the delay in surgery is simply mirroring the underlying morbidities that adversely affect these complications.

\section{Duration of Hospital Stay}

Regardless of the cut-off for delay (e.g., 24, 48, 72 hours) early surgical treatment of a hip fracture injury is associated with a shorter hospital stay based on both unadjusted (24) and adjusted analyses(25) For most studies, as the operative delay increased, so did the mean length of hospital stay. In our study, The mean hospital stay in the $<48$ hours group was $4.66 \pm 0.67$ days, while in the $>48$ hours group it was 5.59 \pm 0.98 days.

It is expected that the longer a patient is required to wait for surgery, the longer they are in the hospital due to the preoperative wait alone. And while early surgery appears to have a large significant effect on reducing the length of stay, it is difficult to establish whether this effect is maintained over and above the preoperative interval. Future studies should calculate and report on the postoperative length of stay in relation to operative timing to resolve this issue.

The Economic Burden Of Surgical Delay

Health care resources incurred by hip fracture patients can includel hospitalization, rehabilitation, chronic care, long term home care, and informal care. Costs are substantially higher for individuals who do not return to the community and require long-term home care or sustain another hip fracture.

Prompt surgical intervention may not only avoid unnecessary discomfort for the patient and facilitate early mobilization and rehabilitation, but also reduce health care costs. Shabat et al. (26)studied the economic effects of delay to surgical fixation in hip fractures and found that spending more resources to expedite the surgery within 48 hours of injury is more cost-effective than delaying surgery past 72 hours.

\section{Conclusion}

The management of hip fractures requires cohesive yet complex care from the time of presentation to the emergency department, through to the radiology, anesthetics, orthopedic surgery, and rehabilitation. Techniques to hasten preoperative care can shorten operative delays, especially in patients that have been medically cleared for surgery. There should be an expedited way to clear the insurance logging which leads to such delay.

Delays in surgeries after hip fracture in elderly individuals are common and attributable to many factors. In hospitals with several surgical specialties, competition for limited surgical capacities (e.g., operating rooms) may determine the timing of surgery. A comprehensive up-to-date evidence could provide the basis to prioritize early hip surgery.

Finally, various protocol for assessing a patient's health status has emerged. Some authors argue that individuals with a poor health status must be medically optimized before any surgery can be performed 
to avoid complications as a consequence of the surgical intervention. To date, it remains unclear if delayed surgical fixation is beneficial for patients with a poor physical status.(27)

A dedicated trauma operating room not only reduced the time to dynamic hip screw and closed femoral nailing procedures, but also allow more of these surgeries to be performed during daytime hours, which may reduce postoperative complications.(28)

\section{Limitations}

Our study has several potential limitations.

Major bulk of our patients who got operated late presented to us one day after the injury. Most of them took primary care elsewhere and chose to get operated in our center for multiple reasons. Delay caused by insurance clearance was also another non-modifiable factor. More number of patients may have shown a better picture. We lacked data on socio-economical status and of functional status prior to admission, two factors that may have affected patient selection for surgery, time to surgery, and the outcome of these elderly patients. One can assume that early surgery may be a surrogate of closer medical attention and reflect a 'better' overall health status of the patient.

\section{Declarations}

Ethics clearance was obtained from Fortis institutional ethics committee.

Conflict of interest

None

\section{References}

1. Sheehan KJ, Sobolev B, Villán Villán YF, et al Patient and system factors of time to surgery after hip fracture: a scoping review BMJ Open 2017;7:e016939. doi: 10.1136/bmjopen-2017-016939.

2. Information Services Division. Clinical decision-making: is the patient fit for theatre? A report from the Scottish Hip Fracture Audit. Edinburgh: ISD Scotland Publications; 2008.

3. Orosz GM, Magaziner J, Hannan EL, Morrison RS, Koval K, Gilbert M, et al. Association of timing of surgery for hip fracture and patient outcomes. JAMA. 2004;291:1738-43.

4. Guyatt GH, Oxman AD, Kunz R, Vist GE, Falck-Ytter Y, Schunemann HJ, et al. What is "quality of evidence" and why is it important to clinicians? BMJ. 2008;336(7651):995-998. doi: 10.1136/bmj.39490.551019.BE.

5. Langley J, Samaranayaka A, Davie G, Campbell AJ. Age, cohort and period effects on hip fracture incidence: analysis and predictions from New Zealand data 1974-2007. Osteoporos Int. 2011;22(1):105-111. doi: 10.1007/s00198-010-1205-6. 
6. Maalouf G, Bachour F, Hlais S, Maalouf NM, Yazbeck P, Yaghi Y, et al. Epidemiology of hip fractures in Lebanon: a nationwide survey. Orthop Traumatol Surg Res. 2013;99(6):675-680. doi: 10.1016/j.otsr.2013.04.009.

7. Riley TR, Gauthier-Lewis ML, Sanchez CK, Douglas JS. Role of agents for reversing the effects of target-specific oral anticoagulants. Am J Health Syst Pharm. 2017;74(2):54-61. doi: 10.2146/ajhp150810.

8. Karres J, Heesakkers NA, Ultee JM, Vrouenraets BC. Predicting 30-day mortality following hip fracture surgery: evaluation of six risk prediction models. Injury. 2015;46(2):371-377. doi:

10.1016/j.injury.2014.11.004.

9. CG, Della Torre PK, Yolland TJ, Shatwell MA. Clopidogrel and hip fractures, is it safe? A systematic reSoo view and meta-analysis. BMC Musculoskelet Disord. 2016;17:136. doi: 10.1186/s12891-0160988-9.

10. Daugaard CL, Jorgensen HL, Riis T, Lauritzen JB, Duus BR, van der Mark S. Is mortality after hip fracture associated with surgical delay or admission during weekends and public holidays? A retrospective study of 38,020 patients. Acta Orthop. 2012;83(6):609-613. doi: 10.3109/17453674.2012.747926.

11. National GC. American Academy of Orthopaedic Surgeons clinical practice guideline on management of hip fractures in the elderly. 2014.

12. Kanis JA, Oden A, McCloskey EV, Johansson H, Wahl DA, Cooper C, et al. A systematic review of hip fracture incidence and probability of fracture worldwide. Osteoporos Int. 2012;23(9):2239-2256. doi: 10.1007/s00198-012-1964-3.

13. Schnell S, Friedman SM, Mendelson DA, Bingham KW, Kates SL. The 1-year mortality of patients treated in a hip fracture program for elders. Geriatr Orthop Surg Rehabil. 2010;1(1):6-14. doi: $10.1177 / 2151458510378105$.

14. Marques A, Lourenco O, da Silva JA, Portuguese Working Group for the Study of the Burden of Hip Fractures in $\mathrm{P}$. The burden of osteoporotic hip fractures in Portugal: costs, health related quality of life and mortality. Osteoporos Int 2015;26(11):2623-2630.

15. Dorotka $R$, Schoechtner $H$, Buchinger $W$. The influence of immediate surgical treatment of proximal femoral fractures on mortality and quality of life: operation within six hours of the fracture versus later than six hours. J Bone Joint Surg Br. 2003;85:1107-13.

16. Kenzora JE, McCarthy RE, Lowell JD, Sledge CB. Hip fracture mortality: relation to age, treatment, preoperative illness, time of surgery, and complications. Clin Orthop. 1984;186:45-56.

17. Zagrodnick J, Kaufner HK. Decreasing risk by individualized timing of surgery of para-articular femoral fractures of the hip in the elderly. Unfallchirurgie. 1990;16:139-43.

18. Sexson SB, Lehner JT. Factors affecting hip fracture mortality. J Orthop Trauma. 1987;1:298-305.

19. Weller I, Wai EK, Jaglal S, Kreder HJ. The effect of hospital type and surgical delay on mortality after surgery for hip fracture. J Bone Joint Surg Br. 2005;87:361-6. 
20. Al-Ani AN, Samuelsson B, Tidermark J, Norling A, Ekstrom W, Cederholm T, et al. Early operation on patients with a hip fracture improved the ability to return to independent living: a prospective study of 850 patients. J Bone Joint Surg Am. 2008;90:1436-42.

21. Sebestyen A, Boncz I, Sandor J, Nyarady J. Effect of surgical delay on early mortality in patients with femoral neck fracture. Int Orthop. 2008;32:375-9.

22. Whinney CM. Do hip fractures need to be repaired within 24 hours of injury? Cleve Clin J Med. 2005;72:250-2.

23. Lefaivre KA, Macadam SA, Davidson DJ, Gandhi R, Chan H, Broekhuyse HM. Length of stay, mortality, morbidity and delay to surgery in hip fractures. J Bone Joint Surg Br. 2009;91:922-7.

24. Nigwekar SU, Rajda J, Navaneethan SD. Hospitalist care and length of stay in patients with hip fracture: a systematic review. Arch Int Med. 2008;168:1010-1.

25. Bhattacharyya T, Vrahas MS, Morrison SM, Kim E, Wiklund RA, Smith RM, et al. The value of the dedicated orthopaedic trauma operating room. J Trauma. 2006;60:1336-40.

26. Shabat S, Heller E, Mann G, Gepstein R, Fredman B, Nyska M. Economic consequences of operative delay for hip fractures in a non-profit institution. Orthopedics. 2003;26:1197-9.

27. Abrahamsen $B$, Vestergaard $P$. Declining incidence of hip fractures and the extent of use of antiosteoporotic therapy in Denmark 1997-2006. Osteoporos Int. 2010;21(3):373-380. doi: 10.1007/s00198-009-0957-3.

28. Mattesi L, Noailles T, Rosencher N, Rouvillain JL. Discontinuation of Plavix(R) (clopidogrel) for hip fracture surgery. A systematic review of the literature. Orthop Traumatol Surg Res. 2016;102(8):1097-1101. doi: 10.1016/j.otsr.2016.08.022.

\section{Tables}




\begin{tabular}{|l|c|c|c|c|}
\hline \multirow{2}{*}{ Age Group } & \multicolumn{2}{|c|}{$<48$ hours } & \multicolumn{2}{c|}{$>48$ hours } \\
\cline { 2 - 5 } & No. & $\%$ & No. & $\%$ \\
\hline $60-70$ years & 14 & 48.3 & 24 & 82.8 \\
\hline $71-80$ years & 13 & 44.8 & 5 & 17.2 \\
\hline$>80$ years & 2 & 6.9 & 0 & 0.0 \\
\hline Total & 29 & 100.0 & 29 & 100.0 \\
\hline Mean \pm SD (years) & $67.10 \pm 4.33$ & $71.17 \pm 6.39$ \\
\hline 't' value, df & \multicolumn{5}{|c|}{$2.838, \mathrm{df}=56$} \\
\hline P value & \multicolumn{5}{|c|}{$0.006 *$} \\
\hline
\end{tabular}

Table No. 1 : Distribution of patients according to age in relation to timing of surgery. Unpaired ' $\mathrm{t}$ ' test applied. $\mathrm{P}$ value $=0.006$, Significant

\begin{tabular}{|l|c|c|c|c|}
\hline & $\begin{array}{c}<48 \text { hours } \\
{[\text { Mean } \pm \text { SD }]}\end{array}$ & $\begin{array}{c}\geq 48 \text { hours } \\
{[\text { Mean } \pm \text { SD }]}\end{array}$ & 't' value & P value \\
\hline Prefall & $46.53 \pm 8.06$ & $52.45 \pm 3.24$ & $-3.669, \mathrm{df}=56$ & \\
\hline At 6 months & $34.93 \pm 6.49$ & $38.16 \pm 5.10$ & $-2.103, \mathrm{df}=56$ & \\
\hline Difference (prefall-6 months) & $-11.59 \pm 5.29$ & $-14.29 \pm 5.43$ & $1.912, \mathrm{df}=56$ & $0.061, \mathrm{NS}$ \\
\hline
\end{tabular}

Table No. 2: Comparison of mean SF-12 physical score at prefall and at 6 months between $<48$ hours and $\geq 48$ hours group. Unpaired ' $\mathrm{t}$ ' test applied. $\mathrm{P}$ value $<0.05$ was taken as statistically significant 


\begin{tabular}{|l|l|l|l|l|}
\hline & $\begin{array}{c}<48 \text { hours } \\
{[\text { Mean } \pm \text { SD }]}\end{array}$ & $\begin{array}{c}>48 \text { hours } \\
{[\text { Mean } \pm \text { SD }]}\end{array}$ & 't' value & P value \\
\hline Prefall & $51.52 \pm 3.32$ & $52.42 \pm 4.81$ & $0.825, \mathrm{df}=56$ & \\
\hline At 6 months & $47.69 \pm 3.09$ & $46.75 \pm 7.18$ & $-0.652, \mathrm{df}=56$ & \\
\hline Difference (prefall-6 months) & $-3.82 \pm 2.32$ & $5.66 \pm 4.06$ & $-2.121, \mathrm{df}=56$ & $0.038^{*}$ \\
\hline
\end{tabular}

Table No. 3 : Comparison of mean SF-12 mental score at prefall and at 6 months between < 48 hours and $>48$ hours group. Unpaired ' $\mathrm{t}$ ' test applied. $\mathrm{P}$ value $<0.05$ was taken as statistically significant

\begin{tabular}{|l|c|c|c|c|}
\hline \multirow{2}{*}{ Reason for Delay } & \multicolumn{2}{|c|}{$<48$ hours } & \multicolumn{2}{|c|}{$>48$ hours } \\
\cline { 2 - 5 } & No. & $\%$ & No. & $\%$ \\
\hline Not applicable & 29 & 100.0 & 0 & 0.0 \\
\hline Late presentation & 0 & 0.0 & 14 & 48.3 \\
\hline Insurance clearance delay & 0 & 0.0 & 7 & 24.1 \\
\hline Medical optimization & 0 & 0.0 & 4 & 13.8 \\
\hline Anti-coagulant therapy & 0 & 0.0 & 3 & 10.3 \\
\hline Theatre / surgeon unavailability & 0 & 0.0 & 1 & 3.4 \\
\hline Total & & & & \\
\hline
\end{tabular}

Table No. 4 : Distribution of patients according to reason for delay 


\begin{tabular}{|l|l|c|c|c|}
\hline & & $\begin{array}{r}\text { Hospital Stay } \\
{[\text { Mean } \pm \text { SD }]}\end{array}$ & 't' value & P value \\
\hline Group & $<48$ hours & $4.66 \pm 0.67$ & $4.217, \mathrm{df}=56$ & $0.000^{*}$ \\
\cline { 2 - 5 } & $>48$ hours & $5.59 \pm 0.98$ & & \\
\hline
\end{tabular}

Table No. 5: Comparison of mean hospital stay between the $<48$ hours and $>48$ hours group. Unpaired ' $\mathrm{t}$ ' test applied. $\mathrm{P}$ value $=0.000$, Significant

\section{Figures}

\section{DISTRIBUTION OF PATIENTS ACCORDING TO AGE AND TIMING OF SURGERY}

\section{Figure 1}

Bar diagram showing distribution of patients according to age and timing of surgery 


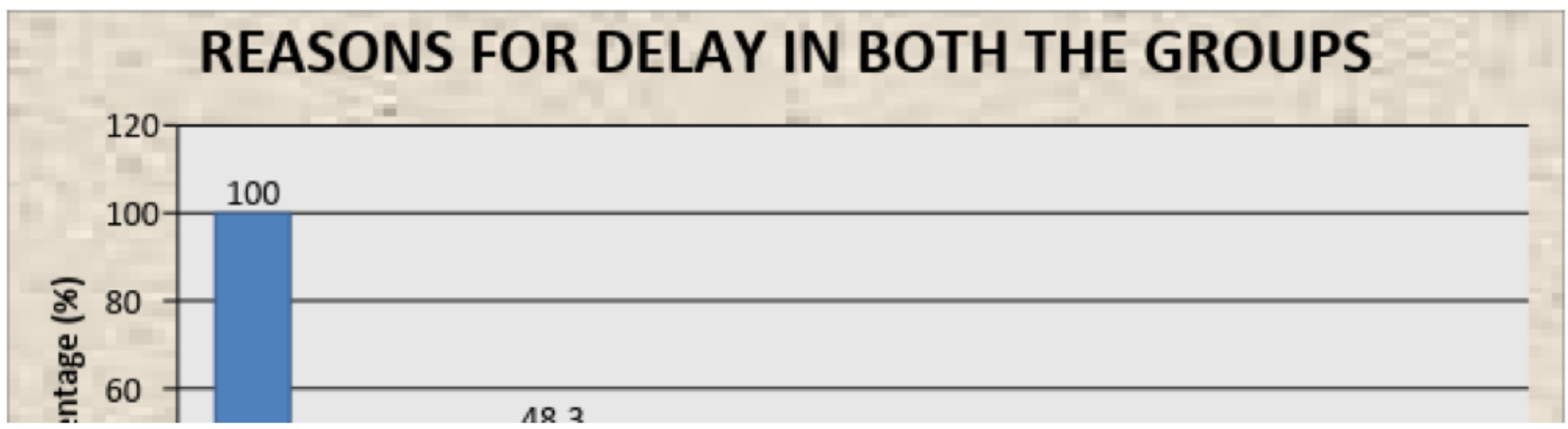

Figure 2

Bar diagram showing reasons for delay between $<48$ hours and $>48$ hours

Figure 3

Bar diagram showing comparison of mean hospital stay (days) between the $<48$ hours and $>48$ hours group 